Bangladesh J. Sci. Ind. Res. 42(2), 217-222, 2007

\title{
Extraction of Henna Leaf Dye and its Dyeing Effects on Textile Fibre
}

\author{
M. M Alam, M. L. Rahman and M. Z. Haque \\ BCSIR Laboratories, Rajshahi-6206, Bangladesh
}

\begin{abstract}
s
Henna plant leaves (Lawsonia inermis) contains dye along with other ingredients. The dye component was extracted and applied on silk fibre in order to investigate the dyeing characteristics, e.g. dyeability, fastness etc. It is found that the dye up take by silk fibre was decreased with the increase of dye concentration. Similarly the absorption of dye was increased with the decrease of dye concentration. The maximum dye absorption has been observed at $0.9 \%$ dye with $10 \%$ alum for the period of 65 minutes at temperature $80^{\circ} \mathrm{C}$ and $\mathrm{pH} 4$. At this optimum condition the dye absorption was $93 \%$. The effects of sunlight in air on silk fibre have been studied to investigate the colourfastness. The colourfastness of dyed silk fibre of water and soap solution at different treatment temperature was satisfactory. Considering dyeability and colourfastness, dye from henna matured leaves was highly applicable on dyeing of silk fibre as well as other protein fibre.
\end{abstract}

\section{Introduction}

Natural dyes have become a part of human life since time of immemorial. The Alchemy of colours started its use from an early time (Vankar, 2000). Use of natural dyes in colouration of textile materials and other purpose is just one of the consequences of increased environmental awareness (Gupta, et. al., 1998). Natural dyes exhibit better biodegradability and generally have a better compatibility with the environment. Also they possess lower toxicity and allergic reactions than synthetic dyes (Kumar and Bharti, 1998).
Today, in the world of growing environmental consciousness, natural colourants have attracted the attention of everyone. Natural dyes used in food are screened for safety but the information is not known for most of the natural dyes used in craft dyeing and with potentially wider use. There is a tendency to assume that consumable natural products are safer and better than synthetic product because they came naturally. The safety of natural dyes needs to be proved if they are used more widely and in commercial process (Kumar and Bharti, 1998). Indigo, a blue dye was extracted from the leaves of leguminous plant (Kalyayini and Jacob, 1998) and 
turmeric (Curcuma longa), a yellow dye, was extracted from the ground root of Indian saffron plants. Turmeric was the only yellow dye that did not require a mordant to fix it on cotton or silk but is sensitive to light, soap and alkali which reduce its value considerably. Logwood (Hancock, 1997) is the most important in black and blue dyeing. It was used on cotton, silk and wood with various mordents for a wide range of colours, but its fastness to light was generally rather poor. Henna (Lawsonia inermis) leaves is an ancient dye, evidence being the Egyptian mummies found in the tombs who had their nails dyed with henna. In the present times, it is used in many countries for dyeing hair, eyebrows and fingernails. During religion festivals and marriages etc. the use of henna for dyeing the palms and fingernails is an auspicious ritual in most Bangladeshi state (Probu and Senthilkumar, 1998). For use a colouring material, henna powder is pasted with water and applied to the part to be dyed. For dyeing hair, it is applied as a pack, it acts as a substantive dye for keratin and imparts an orange red colour. It is harmless and causes no irrigation of skin (Patra, 1998). In our country this plant is used to gardening and dyeing the part of bodies hair and also used in Ayurvedic medicine. The natural dye from turmeric, kapila, and onion coat is applied to silk and wool fabrics dyeing. This three plant gives natural yellow dyes (Gulrjani et. al., 1992).

We report here, the extraction of henna leaves dye and its dyeing effects on silk fibre. The present paper deals with the same.

\section{Materials and Methods}

\section{Collection of plant materials}

The plant Lawsonia inermis (locally known as Mendi) was collected from the BCSIR campus, Rajshahi. The dried mature leaves were crushed into powder for effective extraction.

\section{Collection and sizing of silk fibre}

Mulberry silk (improved multi-voltine variety) fibre was collected from Bangladesh Sericulture Research and Training Institute (BSR \& TI), Rajshahi, Bangladesh. These fibre were sized by a sizing machine from the technological section of BSR \& TI.

\section{Washing drying and pulverizing}

The dried plant leaves were washed with water to remove the adhering materials. The leaves were then dried in an oven at $40^{\circ} \mathrm{C}$ for 24 hours and finely powdered with the help of a grinding machine.

\section{Extraction of dye from henna leaves dried powder (Alkalizalion process)}

$100 \mathrm{~g}$ dried leaves powder sample was taken in saturated $\mathrm{Na}_{2} \mathrm{CO}_{3}$ solution for 24 hours at $\mathrm{pH}$ 8.5-9.2 at room temperature. The solution becomes reddish orange colour. Then percolated with $\mathrm{Na}_{2} \mathrm{CO}_{3}$ solutions until all of the colour has been removed and then filter again. The reddish orange colour was developed due to the presence of alkali.

\section{Acidification process}

The alkali reddish orange colour solution was acidified with hydrochloric acid at pH 4-5. 
After acidification the colour of solution change from reddish orange to yellow orange. This colour is developed by the action of acid.

\section{Extraction with chloroform by liquid-liquid extraction system}

The acidified colour solution was taken into separating funnel and shaken with successive portion of chloroform (until $1 \mathrm{ml}$ of chloroform extract imparted no colour on shaking with $1 \mathrm{ml}$ of sodium carbonate solution). The chloroform extract was dried with anhydrous sodium sulfate and filtered. The chloroform extract produce a orange yellow colour, this solution kept away from light until all the chloroform were vaporized. Then cauliflower like clusters of needles with dark mahogany colour crystalline mass of about $7.05 \mathrm{~g}$ was obtained and is preserved for further investigation.

\section{Deguming of raw silk fibre in alkaline soap solution baths}

For degumming, soap solution (wheel soap) of strength $3.5 \mathrm{~g} /$ litre was prepared and its $\mathrm{pH}$ was adjusted to 10.0-10.5. Degumming was conducted at a temperature $95-100^{\circ} \mathrm{C}$ for 1 hour. Then silk fibre was transferred into 2 nd bath and heated for $45 \mathrm{~min}$. at the same temperature. After degumming the silk fibre was washed well with hot distilled water for 3-4 times.

\section{Method of dyeing of degummed silk fibre with extracted dye}

The extracted dye from the leaves was sparingly soluble in cold water with an orange yellow colour. The dye baths were prepared by adding required amount of dye $(0.9 \%$ on the basis of fibre) and alum as an electrolyte (10\% on the basis of the fibre). The $\mathrm{pH}$ of dye bath was maintained at 3 by adding acetic acid and sodium acetate. The fibre liquor ratio was maintained at 1:20 during dyeing operation. Before immersing the silk fibre in dye bath it was soaked well in distilled water and squeezed for even absorption of dye particles. Dyeing was started at $30^{\circ} \mathrm{C}$, the temperature was then slowly increased almost to the $90^{\circ} \mathrm{C}$ within about $10 \mathrm{~min}$. and continued for $60 \mathrm{~min}$. with occasional stirring by a glass rod and then allowed for further 30 min. as the bath cools down. During dyeing, boiling distilled water was added to the dye baths in order to maintain the level content. After dyeing the fibres were squeezed over dye baths. The fibre material was washed with distilled water (two times) and then dried at room temperature.

\section{Results and Discussion}

The extracted dye was applied on silk fibre and some physical properties of dyed fibre, e.g. effect of dye concentration, electrolyte concentration, time, temperature, colourfastness etc. were also ascertained. The results are summarized in Table I, II, III, IV and V.

From the Table I, it is seen that dye absorption by degummed silk fibre decrease with the increase of dye concentration in the dye bath. This may be explained that the presence of more dye ions hinder absorption of dye to the fibre, where as rare ions favour it. It is to 
Table I. Effect of dye concentration on dyeing of degummed silk with henna leaf dye

\begin{tabular}{c|c|c}
\hline $\begin{array}{c}\text { No. of } \\
\text { expt. }\end{array}$ & $\begin{array}{c}\text { Dye concen- } \\
\text { tration, \% }\end{array}$ & $\begin{array}{c}\text { Dye exhaus- } \\
\text { tions \% }\end{array}$ \\
\hline 1 & 0.0 & 100.00 \\
2 & 0.2 & 97.10 \\
3 & 0.4 & 93.0 \\
4 & 0.6 & 91.62 \\
5 & 0.8 & 88.00 \\
6 & 1.1 & 85.70 \\
7 & 1.3 & 84.10 \\
8 & 1.5 & 81.02 \\
\hline
\end{tabular}

be mentioned that with the increase of dye concentration, the absolute quantity diminishes (Sodov, et. al. 1973; Torpe and Whitely, 1941). The size of dye particles in solution usually depends on temperature, concentration of electrolyte and concentration of dyes. The size of dye particles always increased with an increase in dye concentration (Hancock, 1997). At equilibrium a more or less pronounced selective absorption of the dye by the fibre is observed upto full exhaustion of the dye bath. Forces of interaction of the dye and the fibreous material induce this selective absorption. The exothermic reactions taking place at dyeing confirm the occurrence of the interaction (Chatwal, 1993).

From the experiment it was observed that bright and uniform shades were produced when degummed silk fibre was dyed with $0.8 \%$ dye. Above or below these percentages of dyes dull and uneven shades were obtained. The effective concentration of dye e.g., $0.8 \%$ dye corresponding to $88 \%$ dye exhaustion from the dye bath. The behavior of dye absorption in dyeing of degummed silk fibre depends upon the characteristics of dye towards the fibre.

Table II. Effect of electrolyte concentration on dyeing of degummed silk fibre with extracted henna leaf dye

\begin{tabular}{c|c|c}
\hline $\begin{array}{c}\text { No. of } \\
\text { expt. }\end{array}$ & $\begin{array}{c}\text { Electrolyte } \\
\text { concentration, \% }\end{array}$ & $\begin{array}{c}\text { Dye } \\
\text { exhaustions \% }\end{array}$ \\
\hline 1 & 0 & 32 \\
2 & 2 & 56 \\
3 & 4 & 71 \\
4 & 6 & 79 \\
5 & 8 & 79 \\
6 & 10 & 90 \\
7 & 12 & 90 \\
\hline
\end{tabular}

From the Table II, it is seen that $32 \%$ dye is absorbed from the dye bath containing $0.8 \%$ dye by degummed silk fibre without electrolyte in the dye bath i.e. zero concentration of electrolyte. This is attributed to the fact that in the absence of electrolyte (alum), dyes have a poor affinity towards fibres due to the presence of similar charge group between the fibre and dye.

From the Table II, it is also observed that the absorption of dye increased with the increase of electrolyte concentration in the dye bath up to saturation absorption and beyond this, no change in absorption of dye occurs on further addition of electrolyte. The experiments showed that the absorption reaches saturation absorption when degummed silk fibre is dyed in presence of $10 \%$ alum as electrolyte and 
the corresponding dye exhaustion is $90 \%$. Above or below this percentage of electrolyte shades were uneven and dull. The behaviour of dye absorption depends upon the characteristics of dyes towards the fibre.

Table III. Effect of time on dyeing of degummed silk fibre with extracted henna leaf dye

\begin{tabular}{c|c|c}
\hline $\begin{array}{c}\text { No. of } \\
\text { expt. }\end{array}$ & $\begin{array}{c}\text { Dyeing time } \\
\text { hours }\end{array}$ & $\begin{array}{c}\text { Dye } \\
\text { exhaustions \% }\end{array}$ \\
\hline 1 & 0.5 & 72 \\
2 & 1.0 & 88 \\
3 & 1.5 & 88 \\
4 & 2.0 & 88 \\
5 & 2.5 & 88 \\
\hline
\end{tabular}

From the Table III, it is observed that the absorption of dye by degummed silk fibre increases with the increase of dyeing time and it reaches maximum when dyeing time is 1 hour. The absorption of dye from the dye bath at equilibrium dyeing time is $88 \%$ respectively. The absorption remains the same on further increase of dyeing time. This may be explained that the speed of dye diffusion inside the fibre depends on the size of the dye particles and on the state of the fibre i.e. the smaller the dye particles and greater the fibre swelling.

From the Table IV, it is observed that the absorption of dye by degummed silk fibre increased with the increase of dyeing temperature. It seems that dye exists in solution as a aggregate of various sizes when the temperature of the solution increases the thermal energy coming from outsides impeded aggre gation, and therefore, increased in the
Table IV. Effect of temperature on dyeing of degummed silk fibre with extracted henna leaf dye

\begin{tabular}{c|c|c}
\hline $\begin{array}{c}\text { No. of } \\
\text { expt. }\end{array}$ & $\begin{array}{c}\text { Dyeing } \\
\text { temperature }{ }^{\circ} \mathrm{C}\end{array}$ & $\begin{array}{c}\text { Dye } \\
\text { exhaustions \% }\end{array}$ \\
\hline 1 & 30 (room temp.) & 37 \\
2 & 40 & 56 \\
3 & 50 & 72 \\
4 & 60 & 85 \\
5 & 70 & 90 \\
6 & 80 & 93 \\
7 & 90 & 93 \\
\hline
\end{tabular}

amount of the non-aggregated dye particles in the solution. Hence, the effect of temperature and, consequently increase in the kinetic energy of the dye molecules tends to break up large aggregate into smaller units (Chatwal, 1993; Encyclopedia of Textiles, 1965). It is also evident that, the exhaustion of dye from the dye bath in course of dyeing increases rapidly with the increase of temperature and it reaches maximum when dyeing temperature is about $80^{\circ} \mathrm{C}$. The absorption of dye from the dye bath at equilibrium dyeing temperature is $93 \%$. The absorption remains same on further increase of dyeing temperature.

Dyeing behaviour and nature of raw silk were similar to that of degummed silk fibre. However, dye uptake by raw silk was higher than that of degummed silk. The plausible explanation of such behaviours was that raw silk contains about $25 \%$ sericin, which was removed by degumming. Sericin is a gummy substance, which has a greater water absorbing power. So, raw silk containing sericin, absorbs greater amount of dyes than the degummed silk from the dye bath (Encyclopedia of Textiles, 1965). 
Table V. Colour fastness and change in colour of raw, degummed and dyed silk fibres on exposure to sunlight in air

\begin{tabular}{c|c|c|c}
\hline \multirow{2}{*}{ Exposure time hour } & \multicolumn{3}{|c}{ Fastness grade and colour } \\
\cline { 2 - 4 } & Raw silk & Degummed silk & Dyed silk fibre \\
\hline 0 & 5 golden yellow & 5 white & 5 deep orange yellow \\
50 & 3-4 pale yellow & 5 white & 4-5 orange yellow \\
100 & 2-3 pale yellow & 4-5 yellowish white & 4-5 orange yellow \\
150 & 2 dull yellow & 4-5 yellowish white & 4 orange yellow \\
200 & 2 dull yellow & 4 yellowish white & 3-4 orange yellow \\
250 & 2 dull yellow & 4 yellowish white & 3 light orange yellow \\
\hline
\end{tabular}

It is seen from the Table $\mathrm{V}$ that with the progress of time of exposure to the sunlight in air, the colour of raw silk abruptly changes from golden yellow to dull yellow. But in case of degummed silk the change in colour is not pronounced. Only a slight colour change occurs from white to yellowish white even after 250 hours exposure.

From the Table V, it is also observed that the change in colour of dyed silk fibre occurs within 50-150 hour's exposure and then slight change occurs on further increase of exposure time. This is possible due to the mechanism of the light action produced by the dye on the fibre.

\section{References}

Chatwal, G.R. (1993) Synthetic dyes Himalaya Publishing House, New Delhi, India, PP.1-2.

Encyclopedia of Textiles, (1965) American fabrics magazine, Prentice-Hall, Inc., PP.163-1

Gulrjani, M.L., Gupta, D.B., Agarwal, V. and Jain, M. (1992) Some study of natural yellow dye, The Indian Textile Journal, PP.(a) 50-56., and. (b) 78-84, January and February.

Gupta, V.K. Sachan, R.A., Singh V.P. and Shasma, S.K. (1998) Natural dyes. The Indian Textile
Journal; PP. 16-18, May.

Hancock, H. (1997) Potential for colourarts from plant source in England and wales Vol-2, P.10, October.

Kalyayini, V.K.L.T., and Jacob, M., (1998) Dye from mesta Calyx. The Indian Textile Journal, Vol-1, PP. 86-89.

Kumar, V. and Bharti, B.V. (1998) Eucalyptus Yields dye The Indian Textile Journal, PP. 18-20, February.

Patra, S.K. (1998) Substitute for Banned dyes The Indian Textile Journal, pp. 40, September.

Probu, H.G. and Senthilkumar, K. (1998) Natural dye from Rosa indica The Indian Textile Journal, PP. 78-79.

Sadov. F., Korchagin, M., Matetshy, A. (1973) Chemical technology of fibrous materials, Mir publishers. Moscow, PP. 294-99.

Torpe, J.F., and Whitely, M.A. (1941) Thorpes Dictionery of Applied Chemistry, Vol. 4., (4th ed.), Longmans Green \& Co., PP.143-56.

Vankar, P.S. (2000) The Chemistry of Natural dyes, General article, Resonance PP. 73-80.

Received : May 19, 2005;

Accepted : April 08, 2007 